\title{
Cardiovascular risk in pediatric-onset rheumatological diseases
}

\author{
Julie Barsalou', Timothy J Bradley,2,3 and Earl D Silverman*1,3,4
}

\begin{abstract}
Cardiovascular morbidity and mortality are becoming major health concerns for adults with inflammatory rheumatic diseases. The enhanced atherogenesis in this patient population is promoted by the exposure to traditional risk factors as well as nontraditional cardiovascular insults, such as corticosteroid therapy, chronic inflammation and autoantibodies. Despite definite differences between many adult-onset and pediatric-onset rheumatologic diseases, it is extremely likely that atherosclerosis will become the leading cause of morbidity and mortality in this pediatric patient population. Because cardiovascular events are rare at this young age, surrogate measures of atherosclerosis must be used. The three major noninvasive vascular measures of early atherosclerosis - namely, flow-mediated dilatation, carotid intima-media thickness and pulse wave velocity - can be performed easily on children. Few studies have explored the prevalence of cardiovascular risk factors and even fewer have used the surrogate vascular measures to document signs of early atherosclerosis in children with pediatric-onset rheumatic diseases. The objective of this review is to provide an overview on cardiovascular risk and early atherosclerosis in pediatric-onset systemic lupus erythematosus, juvenile idiopathic arthritis and juvenile dermatomyositis patients, and to review cardiovascular preventive strategies that should be considered in this population.
\end{abstract}

\section{Introduction}

Advances made in the field of pediatric rheumatology over the last decades have led to a significant decrease in

*Correspondence: earl.silverman@sickkids.ca

'Division of Rheumatology, The Hospital for Sick Children, University of Toronto, 555 University Avenue, Toronto, ON, Canada M5G 1X8

Full list of author information is available at the end of the article mortality rates. Patients are now surviving into adulthood and have to face the many challenges imposed by their chronic illness. As a result of better treatments it is likely that cardiovascular disease will emerge as a leading cause of morbidity and mortality. The interplay between traditional cardiovascular risk factors, exposure to corticosteroids and chronic inflammation creates a perfect storm for early atherogenesis in this population.

Atherosclerosis is now being increasingly recognized in adults with inflammatory rheumatic diseases but there is little information pertaining to pediatric-onset rheumatologic conditions [1]. The objectives of this review are to summarize the current state of knowledge on cardiovascular risk and accelerated atherosclerosis in pediatriconset systemic lupus erythematosus (pSLE), juvenile idiopathic arthritis (JIA) and juvenile dermatomyositis (JDM), and to discuss atherosclerosis preventive strategies that should be considered in this patient population.

\section{Measuring atherosclerosis in children}

Although cardiovascular events are the true markers of atherosclerosis in rheumatic diseases, including those in adults, examining cardiovascular risk factors and/or preventive strategies for atherosclerosis are limited by sample size, and therefore surrogate outcome markers (vascular measures of early atherosclerosis) are required. Currently there are three major vascular markers that have been validated as measures of early atherosclerosis: flow-mediated dilatation (FMD), carotid intima-media thickness (CIMT), and pulse wave velocity (PWV).

Endothelial injury is an important initial event in the development of atherosclerosis and therefore measurement of endothelial function can serve as a surrogate marker of atherosclerosis [2]. Vascular ultrasound of the brachial artery under conditions of FMD after reactive hyperemia (endothelium-dependent vasodilatation) and in response to glyceryl trinitrate (endothelium-independent vasodilatation) are noninvasive techniques to measure endothelial function. The severity and longterm risk of coronary artery disease has been well correlated with FMD $[3,4]$.

Ultrasound study of CIMT is a reproducible, validated measurement, and increased CIMT and the presence of 
plaques are predictive of future coronary artery disease and stroke [5]. Meta-analyses and reviews have repeatedly shown that CIMT can predict the risk of future cardiac events and that change over time and a reduction in CIMT is associated with a reduction in incidence of cardiovascular disease (CVD) events [6,7].

PWV is a noninvasive, reliable and reproducible way of measuring early changes in arterial wall stiffness and arterial distensibility [8]. Increased PWV has been demonstrated in both coronary artery disease and cerebrovascular disease [9].

Although data are still lacking on the predictive value of these surrogate markers for future events in pediatric patients, a scientific statement from the American Heart Association stated that these studies detect subclinical vascular disease and therefore can identify children at risk for CVD [10]. Endothelial dysfunction may be found in multiple pediatric rheumatologic diseases and its effects on vascular markers need to be better characterized. Abnormal vascular measures could result from transient, inflammation-induced endothelial dysfunction and not from atherosclerosis per se. Interpretation of these surrogate markers should be made with caution until better methods of distinguishing these phenomena are developed.

\section{Pediatric-onset systemic lupus erythematosus}

PSLE is a life-long autoimmune disease characterized by chronic inflammation, the production of autoantibodies and the frequent use of corticosteroid therapy. Disease onset before age 18 (pSLE) accounts for approximately $15 \%$ of all cases of systemic lupus erythematosus (SLE) [11]. Cardiovascular disease is a leading cause of morbidity and mortality in adult SLE [12]. Although there has been a significant improvement in standardized all-cause mortality rates in adult SLE patients over time, the mortality secondary to atherosclerosis and cardiovascular diseases has not significantly changed [13].

One of the few studies to report on the long-term burden of CVD in PSLE, the Lupus Outcome Study demonstrated that patients with onset of SLE during childhood not only had a similar incidence of myocardial infarction (MI) to subjects with adult-onset disease but that the first MI occurred at a much earlier mean age (32 years) [14]. Using data from this study and agematched cardiovascular data, by early adulthood pSLE patients have a 100 -fold to 300 -fold increased risk of death from CVD as compared with age-matched controls $[15,16]$. However, large prospective long-term cohort studies following patients with pSLE into adulthood are required to determine the true extent of cardiovascular morbidity and mortality. Until these collaborative studies are performed, we need to rely on markers of vascular function as surrogates for atherosclerotic events.

\section{Evidence of early atherosclerosis in pSLE}

Because many years of exposure to atherosclerosis risk factors are required before a cardiovascular event occurs, we cannot rely on the incidence of hard outcomes to assess for atherosclerosis in pSLE and other pediatric rheumatic diseases. The noninvasive vascular assessment techniques of CIMT, FMD and PWV described above therefore play a central role in the detection of early atherosclerosis in pSLE. The major problem when comparing and reviewing studies in PSLE is the heterogeneity of the population studied, the small sample sizes of each study, the different covariates included in the analysis and the differing vascular study protocols used (Table 1) [17-23]. These factors may lead to both type I and type II errors when determining the incidence and prevalence of early atherosclerosis in pSLE. However, despite these limitations, certain conclusions can be made. As seen in studies of adult SLE, PWV may be the best measure to detect the earliest changes of atherosclerosis in pSLE. Furthermore, it has been suggested that PWV and CIMT may measure different vascular damage [24].

Cross-sectional studies of CIMT reported varied results as compared with age-matched controls, probably as a result of the differing vascular study protocols used. Despite these limitations, the average annual rate of progression of CIMT in PSLE patients is small (between 0.0016 and $0.0024 \mathrm{~mm} /$ year) (Table 2). This rate of change in CIMT is similar to that in a study of 247 healthy Caucasian adolescents, which found a rate of change of $0.02 \mathrm{~mm}$ over a 10-year period (average $0.002 \mathrm{~mm} /$ year) [25]. In contrast, in the Atherosclerosis Prevention in Pediatric Lupus Erythematosus (APPLE) trial, the progression rates of all but one of the diverse CIMT measurements carried out on the enrolled placebo-treated pSLE patients showed higher numerical values than those reported in the healthy adolescent cohort, suggesting accelerated atherosclerosis in this large pSLE cohort [26]. More large-scale longitudinal studies are required to determine whether CIMT progression in PSLE truly follows an abnormal trajectory. Adjustment for factors that influence CIMT in childhood, such as age, height, body mass index and blood pressure, should be made to ensure appropriate conclusions are drawn [25].

Elevated PWV has been described in PSLE patients [17]. Interestingly, this later study was carried out on pSLE subjects relatively early in their disease course who had low disease activity. Despite this, a significant difference from healthy controls was found. This might suggest that atherogenesis starts early in these patients and may affect even those with low disease activity.

Measures of brachial artery reactivity (FMD) show the most variation and the significance of these measurements is not clear. Most studies have examined patients 
Table 1. Carotid intima-media thickness in pediatric-onset systemic lupus erythematosus

\begin{tabular}{|c|c|c|c|c|c|}
\hline & $\begin{array}{l}\text { Falaschi and } \\
\text { colleagues [19] }\end{array}$ & $\begin{array}{l}\text { Bowser and } \\
\text { colleagues [18] }\end{array}$ & $\begin{array}{l}\text { Huang and } \\
\text { colleagues [20] }\end{array}$ & $\begin{array}{l}\text { Schanberg and } \\
\text { colleagues [22] }\end{array}$ & $\begin{array}{c}\text { Boros and } \\
\text { colleagues [17] }\end{array}$ \\
\hline \multicolumn{6}{|c|}{ Pediatric-onset systemic lupus erythematosus } \\
\hline Number & 26 & 19 & 76 & 221 & 31 \\
\hline Age (years) & $17.1 \pm 4.4$ & $16.9 \pm 2.3$ & $15.0 \pm 3.5$ & $15.7 \pm 2.6$ & $15.3 \pm 1.9$ \\
\hline Disease duration (years) & $5.5 \pm 3.4$ & $3.2 \pm 2.5$ & $2.6 \pm 2.5$ & $2.6 \pm 2.4$ & $2.6 \pm 0.3$ \\
\hline $\mathrm{CIMT}(\mathrm{mm})$ & $0.57 \pm 0.05$ & $0.48 \pm 0.049$ & $0.63 \pm 0.08$ & $0.59 \pm 0.05$ & Right, $-0.12^{\mathrm{a}}$; left, $-0.10^{\mathrm{a}}$ \\
\hline \multicolumn{6}{|l|}{ Controls } \\
\hline Number & 26 & 15 & 38 & None & 60 \\
\hline Age (years) & Matched & $16.7 \pm 2.1$ & $16.4 \pm 3.9$ & None & $15.9 \pm 1.9$ \\
\hline CIMT (mm) & $0.54 \pm 0.03$ & $0.454 \pm 0.041$ & $0.54 \pm 0.06$ & None & - \\
\hline
\end{tabular}

Values presented as mean \pm standard deviation unless otherwise specified. CIMT, carotid intima-media thickness. ${ }^{2} z$-score.

Table 2. Serial carotid intima-media thickness measurements in pediatric-onset systemic lupus erythematosus

\begin{tabular}{lccccc}
\hline Source & $\begin{array}{c}\text { Number } \\
\text { (\% female) }\end{array}$ & $\begin{array}{c}\text { Age } \\
\text { (years) }\end{array}$ & $\begin{array}{c}\text { Disease duration } \\
\text { (years) }\end{array}$ & Frequency of CIMT assessment & $\begin{array}{c}\text { CIMT progression } \\
\text { (mm/year) }\end{array}$ \\
\hline Huang and colleagues [20] & $76(90 \%)$ & $15.0 \pm 3.5$ & $2.7 \pm 2.5$ & Baseline and every 6 months & \\
Schanberg and colleagues [26] & $108(82 \%)^{\mathrm{c}}$ & $15.8 \pm 2.5$ & $2.5 \pm 2.3$ & Baseline, 6, 12, 24 and 36 months & $0.0016 \pm 0.0016^{\mathrm{b}}$ \\
& $113(84 \%)^{\mathrm{e}}$ & $15.7 \pm 2.8$ & $2.7 \pm 2.4$ & & $0.0024(0.0007,0.0040)^{\mathrm{d}}$ \\
& & & $0.0010(-0.0006,0.0026)^{\mathrm{d}}$ \\
\hline
\end{tabular}

Values presented as mean \pm standard deviation, unless otherwise specified. CIMT, carotid intima-media thickness. aMean number of CIMT assessments performed: 4.6 \pm 1.6. ${ }^{b}$ Mean \pm standard error; CIMT adjusted for age at diagnosis. 'Subjects were in the placebo arm of the Atherosclerosis Prevention in Pediatric Lupus Erythematosus (APPLE) trial. ${ }^{\mathrm{C} C I M T}$ presented as mean (95\% confidence interval). eSubjects were in the atorvastatin arm of the APPLE trial.

with short disease duration and therefore they may not reflect the long-term burden of atherosclerosis in pSLE subjects $[17,23]$.

\section{Risk factors for atherosclerosis}

Even though factors associated with progression of subclinical atherosclerosis have not been well explored in pSLE, traditional and nontraditional risk factors are being increasingly recognized to be present in this patient population.

\section{Traditional risk factors for cardiovascular disease in pSLE}

Dyslipidemia, hypertension, obesity, sedentary lifestyle, diabetes, smoking and family history of early CVD are all considered traditional risk factors for atherosclerosis development. As compared with adult SLE patients, uncontrolled hypertension, diabetes and smoking are not commonly encountered in pediatric patients. In contrast, dyslipidemia - one of the key precursors of early atherosclerosis - has been shown to be present with increased frequency in PSLE when compared with the general pediatric population.

\section{Dyslipidemia}

As early as 1988 it was recognized that both adult and pediatric SLE patients with active disease, prior to corticosteroid therapy, had elevated triglycerides (TGs) and very-low-density lipoprotein-cholesterol and had depressed high-density lipoprotein-cholesterol (HDL-C) and apolipoprotein A-I - often referred to as the active lupus lipid profile $[27,28]$. The lipid profile of elevated TGs and depressed HDL-C is not specific for SLE but rather is common to multiple inflammatory states.

Later studies showed that lipid abnormalities were common in newly diagnosed pSLE patients, prior to the start of corticosteroid treatment [29]. Among a group of 54 recently diagnosed and untreated pSLE subjects, at least one lipid abnormality was found in $63 \%$ of patients elevated TGs in $62 \%$, abnormally low HDL-C in $24 \%$, hypercholesterolemia in $20 \%$ and elevated low density lipoprotein cholesterol (LDL-C) in $4 \%$ - and one patient had an abnormal level of all four lipids [29].

The cross-sectional APPLE trial found mean TG, LDL$\mathrm{C}$ and HDL-C levels that were in the normal ranges [30]. The most common lipid abnormality was also elevated TG levels, found in nearly $30 \%$ of subjects.

The differences between these two studies are probably the result of the lower disease activity, longer disease duration and immunosuppressive therapies of patients in the APPLE trial as compared with the untreated, active patients in the former study.

The dyslipidemia seen in pSLE patients is multifactorial. Cytokines, autoantibodies, medications, dietary intake, renal disease, physical activities and genetics factors are all likely important contributors. As in other diseases, nephrotic-range proteinuria is associated with higher 
total cholesterol and LDL-C levels in pSLE [19]. In addition, other investigators have shown that lower levels of proteinuria (defined as $\geq 200 \mathrm{mg} /$ day but $<3.5 \mathrm{~g} /$ day) were associated with abnormal lipid levels, again demonstrating the importance of renal disease in the dyslipidemia of PSLE [31].

There are few longitudinal studies that have examined serial lipid levels in pSLE subjects [31,32]. In an inception cohort of 139 pSLE patients followed annually from diagnosis up to 3 years, it was shown that the highest levels of total cholesterol, LDL-C and TG and the lowest levels of HDL-C were found at diagnosis, prior to onset of therapy [32]. On follow-up, these same investigators found that the most important factors influencing lipid levels were changes in disease activity and prednisone dose [31]. When controlling for disease activity, a reduction in the prednisone dose was associated with an overall improved lipid profile. A key concept emerges from these studies: when disease activity is brought under control, steroid therapy is being weaned and proteinuria improves, the lipid values normalize. These results suggest that disease control rather than long-term lipid-lowering therapy may be the most important factor to control dyslipidemia in PSLE.

Insulin resistance and metabolic syndrome

Both insulin resistance and metabolic syndrome are present in SLE [32-35]. In pSLE, fasting insulin levels, hemoglobin $\mathrm{A}_{1} \mathrm{C}$ and insulin $\mathrm{C}$-peptide levels were elevated, although Homeostatic Model Assessment for Insulin Resistance values were normal in the majority of patients [17,36]. Obesity, chronic inflammation, and corticosteroid therapy all can contribute to insulin resistance [37-39]. However, elevated fasting insulin levels and hyperinsulinemia were not restricted to patients on corticosteroids or to obese patients. Insulin resistance may also be secondary to a chronic inflammatory state including SLE. A rare cause of insulin resistance (type B insulin resistance) is the presence of antibodies against the insulin receptor. These antibodies result in hyperglycemia, insulin resistance and acanthosis nigricans, and the majority of patients with anti-insulin receptor antibodies have SLE [40]. Of note, patients with anti-insulin receptor antibodies may present with and/or develop hypoglycemia. Despite the presence of insulin resistance and/or metabolic syndrome in patients with pSLE, there is no evidence of an increased prevalence of overt type I or type II diabetes mellitus in pSLE or adult SLE [41]. Patients are, however, at risk for steroid-induced diabetes.

Nontraditional risk factors for cardiovascular disease in pSLE In adult SLE patients, traditional risk factors alone are not sufficient to explain the enhanced risk of cardiovascular events. Indeed, after controlling for the
Framingham risk factors, SLE patients have a 17 -fold increased risk of mortality from coronary heart disease and a 10-fold increase risk of nonfatal MI [42].

\section{Hyperhomocysteinemia}

In studies of otherwise healthy individuals it is not clear whether an elevated homocysteine plasma level is a causal factor or simply a biomarker for atherosclerosis. An etiologic role of hyperhomocysteinemia in atherosclerosis is supported by the multiple proatherogenic effects of hyperhomocysteinemia: induction of endothelial cell dysfunction; increased oxidative stress; and promotion of transcription of proinflammatory cytokine genes via activation of the NF- $\mathrm{kB}$ pathway [43-45]. However, the failure of most trials of homocysteinelowering therapy to decrease cardiovascular risk in large randomized studies has cast doubt on the role of hyperhomocysteinemia in atherosclerosis [46,47]. Studies of both PSLE and adult SLE patients have shown elevated plasma homocysteine levels. However, there was no correlation between elevated homocysteine levels and vascular markers of early atherosclerosis $[17,48,49]$.

\section{Cytokines and adipokines}

An imbalance between endothelial cell damage and repair has been demonstrated to occur in SLE [50,51]. These abnormalities as well as recruitment of macrophages to arteries, enhanced formation of foam cells and platelet activation have all been shown to be induced by type I interferons [52-54]. Increased serum type I interferon activity was shown to be a predictor of abnormal FMD and increased CIMT in adult SLE patients [55]. Similar studies have not been conducted in PSLE but, as the interferon signature is seen in pSLE [56], type I interferon may be an important disease-related factor promoting atherosclerosis.

Elevated levels of other multiple proinflammatory cytokines, including IL-6, IFN $\gamma$ and TNF $\alpha$, have been implicated in the development of atherosclerosis in otherwise healthy populations [57-59]. Although elevated levels of IL-6 are present in adults with SLE and these levels have been shown to correlate with C-reactive protein and abnormal lipid levels, no association between IL- 6 and the presence or progression of atherosclerosis has been found in SLE [60-64].

Adiponectin, leptin and ghrelin all belong to the adipokine family of molecules. Synthesized by adipous tissue, these molecules influence energy homeostasis, lipid metabolism and insulin sensitivity and regulate appetite. Evidence is emerging that adiponectin might be a protective mediator of atherosclerosis, because in nonSLE populations lower levels of adiponectin were associated with a higher risk of MI [65]. In contrast, high levels of adiponectin were observed in adult SLE and 
other inflammatory states. However, there has been no consistent correlation between adipokine levels and early markers of atherosclerosis in adult SLE [66-69]. A prospective study of pSLE patients found no significant difference in adiponectin levels between 105 pSLE patients and a group of healthy controls, although seven pSLE subjects had elevated levels [70]. No studies have explored factors associated with changes in adipokine levels over time or the predictive value of these molecules for the progression of atherosclerosis in PSLE.

Further studies are needed to define whether cytokines, chemokines and adipokines drive the development and progression of atherosclerosis or are protective. These potential biomarkers could guide physicians in stratifying CVD risk in pSLE patients.

\section{Autoantibodies}

Lupus is characterized by circulating antibodies of multiple specificities, including anti-phospholipid, antiendothelial cells, anti-apolipoprotein A-I, anti-HDL-C, anti-lipoprotein(a), anti-oxidized LDL-C and anti-lipoprotein lipase antibodies. The presence of these autoantibodies against these key constituents in the atherosclerosis cascade has been postulated to contribute to the pathogenesis of early atherosclerosis in SLE. In pSLE patients, both antiphospholipid and anti-oxidized LDL-C antibodies have been found $[23,71]$.

\section{Chronic kidney disease}

Lupus nephritis is a common disease manifestation of pSLE. In a minority of patients, renal involvement leads to altered glomerular filtration rate and even to end-stage renal disease. Although not a traditional cardiovascular risk factor, chronic kidney disease is a major contributor to the onset and progression of accelerated atherosclerosis in this subgroup of individuals. Analysis of the US Renal Data System, a database comprising patients on chronic dialysis therapy or patients who had received a renal transplantation, revealed that the risk of death was twice as high in pSLE end-stage renal disease patients when compared with pediatric patients with non-SLErelated end-stage renal disease [72]. Seventy-five percent of those deaths were due to cardiovascular disease and cardiac arrest.

A correlation between the duration of end-stage renal disease and CIMT as well as improvement of CIMT post renal transplantation has been described in pediatric chronic kidney disease patients [73,74]. Similar risk factors for atherosclerosis may be found in both SLE and chronic kidney disease patients: hypertension, dyslipidemia, a chronic inflammatory state, oxidative stress and underlying endothelial dysfunction [75-79]. The coexistence of this double hit and of other chronic kidney disease-specific risk factors, including activation of the renin-angiotensin-aldosterone and sympathetic nervous systems as well as enhanced vascular calcification due to metabolic derangements, lead to a strong proatherogenic milieu. Special attention should therefore be given to pSLE patients with chronic kidney disease as they are at increased risk of cardiovascular disease.

There is a significant gap in knowledge on factors leading to accelerated atherosclerosis and long-term cardiovascular outcomes in pSLE. Identifying key predictors of CVD in this vulnerable population is crucial. This will enable pediatric rheumatologists to identify early on patients at highest risk and to prioritize the implementation of preventive strategies.

\section{Juvenile idiopathic arthritis}

JIA is the most common rheumatologic disease of childhood. JIA encompasses diverse disease subtypes with marked variation in the level of systemic inflammation. Adults with multiple forms of inflammatory arthritis have been shown to have premature atherosclerosis and an increased morbidity and mortality secondary to atherosclerosis [80]. In fact, it has been shown that patients with rheumatoid arthritis probably have a similar risk for atherosclerosis as those with type 2 diabetes mellitus [81]. Despite the diversity of the clinical manifestations of the different JIA subsets, most patients have evidence of chronic inflammation and therefore are probably at risk for early atherosclerosis. Different disease subtypes probably have distinct risk profiles.

There is a paucity of data on the risk or outcome of artherosclerosis in JIA patients with respect to morbidity and mortality. One autopsy study had suggested that 30\% of children with JIA had evidence of atherosclerosis [82]. A small study from Poland showed that the mean CIMT was within the published normal range although increased CIMT was associated with disease duration $[83,84]$. A review of the English-language literature revealed only three reports that assessed surrogate measures of atherosclerosis in children with JIA (Table 3) [85-87]. The first reported study, using magnetic resonance imaging, showed that JIA patients had increased aortic stiffness, lower aortic distensibility and increased PWV, as compared with controls, suggestive of subclinical atherosclerosis [85]. The only association with increased PWV was age. A subsequent comprehensive study showed normal CIMT and PWV but abnormal FMD in JIA patients. Post-hoc analysis suggested that the abnormal FMD was probably related to the inflammatory state of the JIA patients at time of measurement. There was no difference between patients with active and inactive JIA for any of the vascular markers. Not surprisingly, patients with systemic JIA - the subtype of JIA characterized by the most significant chronic inflammation - had the highest CIMT. However, only seven 
Table 3. Vascular measures of atherosclerosis in juvenile idiopathic arthritis

\begin{tabular}{|c|c|c|c|}
\hline & Argyropoulou and colleagues [85] & Vlahos and colleagues [87] & Breda and colleagues [86] \\
\hline$J \mid A(n)$ & 31 & 30 & 38 \\
\hline Oligoarticular subtype & 18 & 15 & - \\
\hline Polyarticular subtype & 6 & 8 & - \\
\hline Systemic subtype & 7 & 7 & - \\
\hline Age (years) & 13.6 (3.4 to 26.2$)$ & $12.0 \pm 3.0$ & $7.1 \pm 2.4$ \\
\hline Disease duration (years) & $9.1 \pm 5.4$ & $6.6 \pm 3.8$ & 22.9 \\
\hline CIMT (mm) & Not reported & $\begin{array}{c}0.46 \pm 0.03 \text { (patients) vs. } \\
0.45 \pm 0.03 \text { (controls) }\end{array}$ & $\begin{array}{c}0.38 \pm 0.05 \text { (patients) }^{\mathrm{a}} \mathrm{vs} \\
0.31 \pm 0.05 \text { (controls) }\end{array}$ \\
\hline FMD (\%) & Not reported & $\begin{array}{c}7.10 \pm 2.23 \text { (patients) }{ }^{b} \text { vs. } \\
9.93 \pm 3.90 \text { (controls) }\end{array}$ & Not reported \\
\hline $\mathrm{PWV}(\mathrm{m} / \mathrm{s})$ & $\begin{array}{c}3.68 \pm 1.59 \text { (patients) }^{\mathrm{v}} \mathrm{vs} . \\
1.38 \pm 0.54 \text { (controls) }^{-1.5}\end{array}$ & $\begin{array}{c}5.5 \pm 0.9 \text { (patients) vs. } \\
5.7 \pm 1.0 \text { (controls) }\end{array}$ & Not reported \\
\hline Inflammatory markers & Not reported & Increased & Increased \\
\hline Cytokines/endothelial activation & Not reported & Increased & Increased \\
\hline
\end{tabular}

Values are presented as mean \pm standard deviation or median (range), unless otherwise specified. CIMT, carotid intima-media thickness; FMD, flow-mediated dilatation; JIA, juvenile idiopathic arthritis; PWV, pulse wave velocity. ${ }^{a}$ Difference from controls is statistically significant $(P<0.01)$. ${ }^{b}$ Difference from controls is statistically significant $(P=0.001)$.

systemic JIA patients were tested [87]. The most recent study reported that prepubertal JIA patients (only oligoarticular and polyarticular subtypes) had significantly increased CIMT as compared with controls. At follow-up after 1 year of individualized therapy that was associated with improved disease control and decreased inflammation, there was a significant decrease in CIMT [86]. In this study, CIMT was associated with LDL-C and IL-1 levels. Overall, the small number of patients and the predominance of subjects with oligoarticular JIA, the least inflammatory subtype, make the generalizability of these findings questionable. Children with systemic JIA are probably at a much higher risk of accelerated atherosclerosis than those with oligoarticular or polyarticular JIA. Future studies should address the question by specific disease subtypes.

Similar issues arise when studies on the prevalence of traditional risk factors for atherosclerosis are examined. The few studies reporting lipid levels of JIA patients included children with different disease subtypes, disease activity levels and corticosteroid doses. This heterogeneity probably explains the contradictory findings of the active inflammatory lipid profile of high TGs and very-low-density lipoprotein-cholesterol and lower levels of HDL-C, LDL-C and total cholesterol found in some, but not all, studies of JIA [86-93]. Overall it is difficult to determine the effect of disease and disease activity on the lipid profile in each distinct JIA subtype. Moreover, biologic therapies might adversely impact the lipid profile, as seen in systemic-onset JIA patients treated with tocilizumab [94]. Further large-scale studies should be conducted to clarify the burden and trajectory of dyslipidemia in the different JIA subtypes.
Similar to other rheumatic diseases, patients with JIA have evidence of elevated proinflammatory cytokines and chemokines. The degree of elevation is dependent on the subtype and level of disease activity. Most, but not all, studies have shown elevated homocysteinemia levels in JIA patients [95-97]. One study showed a correlation of homocysteine with CIMT [83]. Elevated levels of omentin, an insulin-sensitizing adipokine, were demonstrated in patients with JIA [98]. Omentin has important effects on endothelium as it causes vasodilatation of blood vessels and attenuates many proinflammatory signaling pathways in endothelial cells, including the TNF pathway $[99,100]$. The elevated circulating levels seen in JIA may therefore act as a counter-regulatory mechanism to attenuate the proatherosclerotic effects of TNF and other mediators of chronic inflammation. The importance of leptin in atherosclerosis in JIA is not clear because the two studies reported showed opposite results $[101,102]$.

Limitation to performing physical activities due to arthritis and its associated musculoskeletal complications, as well as corticosteroid usage, renders JIA patients susceptible to weight gain. A recent study found that patients with JIA had higher body mass index, fat percentages and truncal fat than age-matched and sexmatched controls [103]. Despite the challenges to regular physical activities in this patient population, children with JIA should be strongly encouraged to engage in an exercise program.

Data on other nontraditional risk factors in this pediatric population are lacking. As many patients will continue to have active disease into adulthood, the need to expand research on the prevalence of atherosclerosis 
risk factors and incidence of CVD in JIA is important. This is especially true for patients with systemic and polyarticular JIA subtypes, as these patients are at highest risk for chronic inflammation and prolonged use of corticortisteroids.

\section{Juvenile dermatomyositis}

JDM is an inflammatory disease characterized by typical cutaneous rashes, symmetrical proximal muscle weakness, raised serum levels of muscle enzymes and a vasculopathy. Few studies have assessed early atherosclerosis in JDM patients. A study of adults with dermatomyositis or polymyositis demonstrated higher risks of acute MI and stroke when compared with the general population [104]. A recent study from Sweden showed that adults with polymyositis/dermatomyositis had a standardized incidence ratio of 1.92 for the development of coronary heart disease as compared with age- and sexmatched controls [105]. The only study to examine the risk of atherosclerosis in JDM compared CIMT and FMD of eight adults with a history of JDM with eight healthy adults [106]. The CIMT was higher in JDM patients despite the fact that they were younger and had lower body mass index than controls.

Acquired lipodystrophy has gained recognition in JDM patients with reported prevalence rates ranging from 8 to $40 \%$ [107-109]. This condition leads to loss of subcutaneous fat and is associated with diverse metabolic abnormalities such as dyslipidemia, abnormal leptin levels, insulin resistance and overt diabetes. The extent to which these abnormalities impact on accelerated atherosclerosis remains unknown. Future work should evaluate whether lipodystrophy is a predictor of cardiovascular events in the JDM population.

A study of children with myositis showed that $41 \%$ had elevated fasting insulin levels with $25 \%$ meeting criteria for metabolic syndrome, $47 \%$ had elevated TG and 17\% had abnormal cholesterol, LDL-C or HDL-C levels [110]. The previous mentioned study of CIMT was also performed to document risk factors for atherosclerosis in JDM [106]. These same patients had higher blood pressure values, higher prevalence of abnormal HDL-C levels and lower adiponectin levels compared with controls. Two patients fulfilled criteria for the metabolic syndrome and $63 \%$ had lipodystrophy [107]. Atherogenic risk factors are thus clearly present in JDM children. Again, future studies should address the long-term incidence of CVD and better delineate predictors of cardiovascular morbidity and mortality in JDM.

Although JDM and pSLE are clearly two distinct entities, a parallel can be established between these conditions with respect to cardiovascular risk factors. Type I interferons have been implicated in the pathogenesis of both JDM and SLE [111]. Although no studies have looked at the effect of these cytokines on the development of atherosclerosis in JDM, it is reasonable to assume that they have similar effects on the endothelium to those seen in SLE. Similarly, chronic insult to the endothelium precipitated by the underlying vasculopathy and chronic inflammation probably leads to early atherosclerosis in JDM, as seen in SLE. Additionally, long-term corticosteroid therapy probably results in similar metabolic derangements such as weight gain, insulin resistance and dyslipidemia. Both diseases also lead to disabilities resulting in a decreased ability to practice regular aerobic activities.

\section{Prevention strategies}

Atherosclerosis is known to begin in childhood. Moreover, longitudinal studies have demonstrated that the presence of cardiovascular risk factors in childhood is associated with higher CIMT in young adults $[112,113]$. Children with inflammatory diseases have an increased prevalence of traditional risk factors and the extra burden of nontraditional risk factors for atherosclerosis. Hence, thorough ongoing cardiovascular risk assessment should be performed routinely in children with chronic rheumatologic diseases. Long-term cardiovascular morbidity and mortality should be discussed with patients and their families soon after disclosure of the diagnosis to educate patients and facilitate the application of preventive strategies.

\section{Traditional risk factor-related preventive measures}

Overweight and obesity are common in patients with pediatric rheumatic diseases, and in particular in patients on corticosteroid therapy. The general unwellness secondary to systemic inflammation, the arthritis, the psychological impact of having a chronic disease and the development of cushingoid features all potentially contribute to sedentary lifestyle. The benefits of physical activity on many of the traditional cardiovascular risk factors are well established and regular exercise should be encouraged. Children unable to perform aerobic exercises to the desired level should be encouraged to pursue a regular exercise routine adapted to their clinical status, and intensity should be increased as tolerated. A healthy balanced diet should be promoted in all patients. Nutritional and physical activity counseling should be regarded as management priorities. Smoking status should be assessed regularly and smoking cessation support offered.

Blood pressure should be monitored at each clinic visit and home blood pressure monitoring should be implemented in those with borderline elevated or elevated values or with kidney disease. Periodic monitoring of the blood glucose level should be performed with special attention to patients on a high dosage of 
corticosteroids, overweight or obese, or with a family history of type II diabetes mellitus.

A baseline pretreatment lipid level should be measured and serial measurements performed. This may not apply to certain disease subtypes, such as oligoarticular JIA, where the risk of dyslipidemia is probably similar to that in the general pediatric population. However, there are currently no clear guidelines on the frequency of dyslipidemia screening and the threshold at which specific treatment should be contemplated for patients with pediatric rheumatic diseases has not been defined [114]. The APPLE trial, the only study to prospectively assess the use of a statin to reduce the progression of atherosclerosis, as measured by CIMT in PSLE, did not find a significant difference in progression of CIMT between the statin-treated and placebo-treated patient groups [26]. However, secondary analyses did show a trend in favor of atorvastatin for other CIMT endpoints. Further studies are required to determine the role of lipid-lowering therapy in pediatric rheumatology.

The use of antimalarial agents in pSLE and JDM provides a dual benefit: not only do these agents help to keep the disease inactive, but they also exert beneficial effects on lipid levels and glucose tolerance [115-118].

\section{Nontraditional risk factor-related preventive measures}

A key message that emanates from SLE studies and that probably applies to other inflammatory conditions is that adequately treating the primary disease will improve many of the cardiovascular risk factors. Control of systemic inflammation will decrease production of proatherogenic cytokines, chemokines, adipokines and autoantibodies, thereby decreasing the burden of proatherogenic insults. Judicious use of corticosteroid might tilt the balance in favor of benefits. This hypothesis might explain why the use of moderate doses of corticosteroid was negatively correlated with CIMT in the APPLE study [26].

Therapies used in the treatment of rheumatic disease have been associated with a decrease in atherosclerotic burden. Anti-TNF $\alpha$ therapies have been associated with decreased CIMT [119]. Although B cells have been found to have atheroprotective effects, B-cell deficiency in murine models of atherosclerosis results in a decrease in plaque size $[120,121]$. Whether this effect is also true in humans and whether other anti-B-cell treatments have the same effect are not clear. As there are increasing data on the importance of type I interferons in atherosclerosis and disease activity, it will be interestingly to see whether anti-interferon therapy will affect atherosclerosis. These biologic therapeutic avenues offer the potential for additional tools in atherosclerosis prevention and therapy. Whether the primary effect on atherosclerosis is secondary to decreasing inflammation or whether there are intrinsic factors related to these molecules is not clear.
Azathioprine has been linked to atherosclerosis while methotrexate and mycophenolate mofetil may offer protection [122-125]. However, the effects of these three immunosuppressive agents on atherosclerosis need further study. The use of angiotensin-converting enzyme inhibitors and angiotensin receptor blocking agents in patients with proteinuria and/or hypertension will not only offer benefits by their direct action on these cardiovascular risk factors but probably also via downregulation of the renin-angiotensin system, which is also implicated in the genesis of atherosclerosis.

\section{Conclusion}

Children with chronic rheumatologic diseases are exposed to a vast array of proatherogenic insults, but the prevalence and natural history of accelerated atherosclerosis in the majority of these children remains poorly defined. However, it is becoming more apparent that cardiovascular disease results in significant morbidity and mortality in these patients in adulthood. Identifying key risk factors, developing disease-specific stratification algorithms and implementing interventions to prevent atherosclerosis are therefore important. The predictive value of surrogate measures of atherosclerosis should be specifically studied in this pediatric population. Efforts should be made to identify novel biomarkers that would assist us in quantifying the atherosclerotic burden and to follow its trajectory. Prospective, multicenter cohort studies addressing these important issues are urgently needed. Pediatric rheumatology researchers have shown that assembling large national and international cohorts of patients with rheumatic diseases is feasible $[15,126,127]$. Hopefully, collaborative efforts among the pediatric and adult rheumatology communities will ultimately lead to improved long-term cardiovascular outcomes in patients with pediatric-onset rheumatologic diseases.

\section{Abbreviations \\ APPLE, Atherosclerosis Prevention in Pediatric Lupus Erythematosus; CIMT, carotid intima-media thickness; CVD, cardiovascular disease; FMD, flow-mediated dilatation; HDL-C, high-density lipoprotein-cholesterol; IFN, interferon; IL, interleukin; JDM, juvenile dermatomyositis; JIA, juvenile idiopathic arthritis; LDL-C, low-density lipoprotein-cholesterol; MI, myocardial infarction; NF, nuclear factor; pSLE, pediatric-onset systemic lupus erythematosus; PWV, pulse wave velocity; SLE, systemic lupus erythematosus; TG, triglyceride; TNF, tumor necrosis factor.}

\section{Competing interests}

JB receives funding for a Lupus Fellowship through GlaxoSmithKline Inc., the Canadian Network for Improved Outcomes in Systemic Lupus Erythematosus, the Canadian Rheumatology Association and The Arthritis Society. EDS holds the Ho Family Chair in Autoimmune Diseases. TJB declares that he has no competing interests.

\section{Author details}

'Division of Rheumatology, The Hospital for Sick Children, University of Toronto, 555 University Avenue, Toronto, ON, Canada M5G 1X8. ²Division of Cardiology, The Hospital for Sick Children, University of Toronto, 555 University 
Avenue, Toronto, ON, Canada M5G 1X8. ${ }^{3}$ Department of Pediatrics, University of Toronto, 555 University Avenue, Toronto, ON, Canada M5G 1X8. ${ }^{4}$ Hospital for Sick Children Research Institute, 555 University Avenue, Toronto, ON, Canada M5G 1X8.

\section{Published: 22 May 2013}

\section{References}

1. Roifman I, Beck PL, Anderson TJ, Eisenberg MJ, Genest J: Chronic inflammatory diseases and cardiovascular risk: a systematic review. Can J Cardiol 2011, 27:174-182

2. Cines DB, Pollak ES, Buck CA, Loscalzo J, Zimmerman GA, McEver RP, Pober JS, Wick TM, Konkle BA, Schwartz BS, Barnathan ES, McCrae KR, Hug BA, Schmidt AM, Stern DM: Endothelial cells in physiology and in the pathophysiology of vascular disorders. Blood 1998, 91:3527-3561.

3. Juonala M, Kahonen M, Laitinen T, Hutri-Kahonen N, Jokinen E, Taittonen L, Pietikainen M, Helenius H, Viikari JS, Raitakari OT: Effect of age and sex on carotid intima-media thickness, elasticity and brachial endothelial function in healthy adults: the cardiovascular risk in Young Finns Study. Eur Heart J 2008, 29:1198-1206.

4. Benjamin EJ, Larson MG, Keyes MJ, Mitchell GF, Vasan RS, Keaney JF, Jr, Lehman BT, Fan S, Osypiuk E, Vita JA: Clinical correlates and heritability of flow-mediated dilation in the community: the Framingham Heart Study. Circulation 2004, 109:613-619.

5. Bots ML, Grobbee DE, Hofman A, Witteman JC: Common carotid intimamedia thickness and risk of acute myocardial infarction: the role of lumen diameter. Stroke 2005, 36:762-767.

6. Lorenz MW, Markus HS, Bots ML, Rosvall M, Sitzer M: Prediction of clinical cardiovascular events with carotid intima-media thickness: a systematic review and meta-analysis. Circulation 2007, 115:459-467.

7. Nguyen QM, Toprak A, Xu JH, Srinivasan SR, Chen W, Berenson GS Progression of segment-specific carotid artery intima-media thickness in young adults (from the Bogalusa Heart Study). Am J Cardiol 2011, 107:114-119.

8. Aatola H, Hutri-Kahonen N, Juonala M, Viikari JS, Hulkkonen J, Laitinen T, Taittonen L, Lehtimaki T, Raitakari OT, Kahonen M: Lifetime risk factors and arterial pulse wave velocity in adulthood: the cardiovascular risk in young Finns study. Hypertension 2010, 55:806-811.

9. Tsuchikura S, Shoji T, Kimoto E, Shinohara K, Hatsuda S, Koyama H, Emoto M, Nishizawa Y: Central versus peripheral arterial stiffness in association with coronary, cerebral and peripheral arterial disease. Atherosclerosis 2010, 211:480-485.

10. Urbina EM, Williams RV, Alpert BS, Collins RT, Daniels SR, Hayman L, Jacobson M, Mahoney L, Mietus-Snyder M, Rocchini A, Steinberger J, McCrindle B; American Heart Association Atherosclerosis, Hypertension, and Obesity in Youth Committee of the Council on Cardiovascular Disease in the Young: Noninvasive assessment of subclinical atherosclerosis in children and adolescents: recommendations for standard assessment for clinical research: a scientific statement from the American Heart Association. Hypertension 2009, 54:919-950.

11. Tucker $\mathrm{L}$ : Review: Making the diagnosis of systemic lupus erythematosus in children and adolescents. Lupus 2007, 16:546-549.

12. Tyrrell PN, Beyene J, Feldman BM, McCrindle BW, Silverman ED, Bradley TJ: Rheumatic disease and carotid intima-media thickness: a systematic review and meta-analysis. Arterioscler Thromb Vasc Biol 2010, 30:1014-1026.

13. Urowitz MB, Gladman D, Ibanez D, Fortin P, Sanchez-Guerrero J, Bae S, Clarke A, Bernatsky S, Gordon C, Hanly J, Wallace D, Isenberg D, Ginzler E, Merrill J, Alarcon G, Steinsson K, Petri M, Dooley MA, Bruce I, Manzi S, Khamashta M, Ramsey-Goldman R, Zoma A, Sturfelt G, Nived O, Maddison P, Font J, van Vollenhoven R, Aranow C, Kalunian K, Stoll T, Buyon J: Clinical manifestations and coronary artery disease risk factors at diagnosis of systemic lupus erythematosus: data from an international inception cohort. Lupus 2007, 16:731-735

14. Hersh $A O$, von Scheven E, Yazdany J, Panopalis P, Trupin L, Julian L, Katz P, Criswell LA, Yelin E: Differences in long-term disease activity and treatment of adult patients with childhood- and adult-onset systemic lupus erythematosus. Arthritis Rheum 2009, 61:13-20.

15. Hersh AO, Trupin L, Yazdany J, Panopalis P, Julian L, Katz P, Criswell LA, Yelin E: Childhood-onset disease as a predictor of mortality in an adult cohort of patients with systemic lupus erythematosus. Arthritis Care Res 2010, 62:1152-1159
16. California Department of Health Statistics: Death Statistics Data Table - Leading Causes of Female Deaths by Age and Race/Ethnic Group and Rates for All Races Combined. California, USA: California Department of Health Statistics; 2010.

17. Boros CA, Bradley TJ, Cheung MM, Bargman JM, Russell JL, McCrindle BW, Adeli K, Hamilton J, Silverman ED: Early determinants of atherosclerosis in paediatric systemic lupus erythematosus. Clin Exp Rheumatol 2011, 29:575-581.

18. Bowser CS, Kumar S, Salciccioli L, Kutlin A, Lazar J, Rahim I, Suss A, Kohlhoff S, Hammerschlag MR, Moallem HJ: Absence of Chlamydia pneumoniae and signs of atherosclerotic cardiovascular disease in adolescents with systemic lupus erythematosus. Pediatr Cardiol 2008, 29:545-551.

19. Falaschi F, Ravelli A, Martignoni A, Migliavacca D, Sartori M, Pistorio A, Perani G, Martini A: Nephrotic-range proteinuria, the major risk factor for early atherosclerosis in juvenile-onset systemic lupus erythematosus. Arthritis Rheum 2000, 43:1405-1409.

20. Huang YL, Chung HT, Chang CJ, Yeh KW, Chen LC, Huang JL: Lymphopenia is a risk factor in the progression of carotid intima-media thickness in juvenile-onset systemic lupus erythematosus. Arthritis Rheum 2009, 60:3766-3775.

21. Nascif AK, Hilario MO, Terreri MT, Aizen SA, D'Almeida V, Plavnik FL, de Jesus Christofalo DM: Endothelial function analysis and atherosclerotic risk factors in adolescents with systemic lupus erythematosus. Int J Adolesc Med Health 2007, 19:497-505.

22. Schanberg LE, Sandborg C, Barnhart HX, Ardoin SP, Yow E, Evans GW, Mieszkalski KL, llowite NT, Eberhard A, Levy DM, Kimura Y, von Scheven E, Silverman E, Bowyer SL, Punaro L, Singer NG, Sherry DD, McCurdy D, KleinGitelman M, Wallace C, Silver R, Wagner-Weiner L, Higgins GC, Brunner HI, Jung L, Soep JB, Reed A; Atherosclerosis Prevention in Pediatric Lupus Erythematosus Investigators: Premature atherosclerosis in pediatric systemic lupus erythematosus: risk factors for increased carotid intimamedia thickness in the atherosclerosis prevention in pediatric lupus erythematosus cohort. Arthritis Rheum 2009, 60:1496-1507.

23. Soep JB, Mietus-Snyder M, Malloy MJ, Witztum JL, von Scheven E: Assessment of atherosclerotic risk factors and endothelial function in children and young adults with pediatric-onset systemic lupus erythematosus. Arthritis Rheum 2004, 51:451-457.

24. Oren A, Vos LE, Uiterwaal CS, Grobbee DE, Bots ML: Cardiovascular risk factors and increased carotid intima-media thickness in healthy young adults: the Atherosclerosis Risk in Young Adults (ARYA) Study. Arch Intern Med 2003, 163:1787-1792

25. Jourdan C, Wuhl E, Litwin M, Fahr K, Trelewicz J, Jobs K, Schenk JP, Grenda R, Mehls O, Tröger J, Schaefer F: Normative values for intima-media thickness and distensibility of large arteries in healthy adolescents. J Hypertens 2005, 23:1707-1715.

26. Schanberg LE, Sandborg C, Barnhart HX, Ardoin SP, Yow E, Evans GW, Mieszkalski KL, llowite NT, Eberhard A, Imundo LF, Kimura Y, von Scheven E, Silverman E, Bowyer SL, Punaro M, Singer NG, Sherry DD, McCurdy D, KleinGitelman M, Wallace C, Silver R, Wagner-Weiner L, Higgins GC, Brunner HI, Jung L, Soep JB, Reed AM, Provenzale J, Thompson SD; Atherosclerosis Prevention in Pediatric Lupus Erythematosus Investigators: Use of atorvastatin in systemic lupus erythematosus in children and adolescents. Arthritis Rheum 2012, 64:285-296.

27. Ilowite NT, Samuel P, Ginzler E, Jacobson MS: Dyslipoproteinemia in pediatric systemic lupus erythematosus. Arthritis Rheum 1988, 31:859-863.

28. Borba EF, Bonfa E: Dyslipoproteinemias in systemic lupus erythematosus: influence of disease, activity, and anticardiolipin antibodies. Lupus 1997 6:533-539.

29. Tyrrell PN, Beyene J, Benseler SM, Sarkissian T, Silverman ED: Predictors of lipid abnormalities in children with new-onset systemic lupus erythematosus. J Rheumatol 2007, 34:2112-2119.

30. Ardoin SP, Schanberg LE, Sandborg C, Yow E, Barnhart HX, Mieszkalski K, Ilowite NT, von Scheven E, Eberhard A, Levy DM, Kimura Y, Silverman E, Bowyer SL, Punaro L, Singer NG, Sherry DD, McCurdy D, Klein-Gitelman M, Wallace C, Silver R, Wagner-Weiner L, Higgins GC, Brunner HI, Jung LK, Imundo L,Soep JB, Reed AM; APPLE Investigators: Laboratory markers of cardiovascular risk in pediatric SLE: the APPLE baseline cohort. Lupus 2010 19:1315-1325

31. Sarkissian T, Beyene J, Feldman B, McCrindle B, Silverman ED: Longitudinal examination of lipid profiles in pediatric systemic lupus erythematosus. Arthritis Rheum 2007, 56:631-638.

32. Sarkissian T, Beyenne J, Feldman B, Adeli K, Silverman E: The complex nature 
of the interaction between disease activity and therapy on the lipid profile in patients with pediatric systemic lupus erythematosus. Arthritis Rheum 2006, 54:1283-1290.

33. Sabio JM, Zamora-Pasadas M, Jimenez-Jaimez J, Albadalejo F, Vargas-Hitos J, Rodriguez del Aguila MD, Hidalgo-Tenorio C, Gonzalez-Gay MA, JimenezAlonso J: Metabolic syndrome in patients with systemic lupus erythematosus from Southern Spain. Lupus 2008, 17:849-859.

34. El Magadmi M, Ahmad Y, Turkie W, Yates AP, Sheikh N, Bernstein RM, Durrington PN, Laing I, Bruce IN: Hyperinsulinemia, insulin resistance, and circulating oxidized low density lipoprotein in women with systemic lupus erythematosus. J Rheumatol 2006, 33:50-56

35. Zeng YJ, Zeng FQ, Dai L, Yang C, Lin BZ, Zheng DH, Liu D, Yan L, Ren M, Cheng $\mathrm{H}$ : Characteristics and risk factors for hyperglycemia in Chinese female patients with systemic lupus erythematosus. Lupus 2010, 19:1344-1350

36. Posadas-Romero C, Torres-Tamayo M, Zamora-Gonzalez J, Aguilar-Herrera BE, Posadas-Sanchez R, Cardoso-Saldana G, Ladron de Guevara G, Solis-Vallejo E, El Hafidi M: High insulin levels and increased low-density lipoprotein oxidizability in pediatric patients with systemic lupus erythematosus. Arthritis Rheum 2004, 50:160-165.

37. Steinberg GR, Michell BJ, van Denderen BJ, Watt MJ, Carey AL, Fam BC, Andrikopoulos S, Proietto J, Gorgun CZ, Carling, Hotamisligil GS, Febbraio MA, Kay TW, Kemp BE: Tumor necrosis factor alpha-induced skeletal muscle insulin resistance involves suppression of AMP-kinase signaling. Cell Metab 2006, 4:465-474

38. Emanuela F, Grazia M, Marco de R, Maria Paola L, Giorgio F, Marco B: Inflammation as a link between obesity and metabolic syndrome. J Nutr Metab 2012, 2012:476380

39. van Raalte DH, Ouwens DM, Diamant M: Novel insights into glucocorticoidmediated diabetogenic effects: towards expansion of therapeutic options? Eur J Clin Invest 2009, 39:81-93.

40. Arioglu E, Andewelt A, Diabo C, Bell M, Taylor SI, Gorden P: Clinical course of the syndrome of autoantibodies to the insulin receptor (type $B$ insulin resistance): a 28-year perspective. Medicine (Baltimore) 2002, 81:87-100.

41. Cortes S, Chambers S, Jeronimo A, Isenberg D: Diabetes mellitus complicating systemic lupus erythematosus - analysis of the UCL lupus cohort and review of the literature. Lupus 2008, 17:977-980.

42. Esdaile JM, Abrahamowicz M, Grodzicky T, Li Y, Panaritis C, du Berger R, Cote R, Grover SA, Fortin PR, Clarke AE, Senécal JL: Traditional Framingham risk factors fail to fully account for accelerated atherosclerosis in systemic lupus erythematosus. Arthritis Rheum 2001, 44:2331-2337.

43. Weiss N, Keller C, Hoffmann U, Loscalzo J: Endothelial dysfunction and atherothrombosis in mild hyperhomocysteinemia. Vasc Med 2002, 7:227-239.

44. Ungvari Z, Csiszar A, Edwards JG, Kaminski PM, Wolin MS, Kaley G, Koller A: Increased superoxide production in coronary arteries in hyperhomocysteinemia: role of tumor necrosis factor-alpha, NAD(P)H oxidase, and inducible nitric oxide synthase. Arterioscler Thromb Vasc Biol 2003, 23:418-424

45. Au-Yeung KK, Woo CW, Sung FL, Yip JC, Siow YL, O K: Hyperhomocysteinemia activates nuclear factor-kappaB in endothelial cells via oxidative stress. Circ Res 2004, 94:28-36.

46. Kalra DK: Homocysteine and cardiovascular disease. Curr Atheroscler Rep 2004, 6:101-106.

47. Saposnik G, Ray JG, Sheridan P, McQueen M, Lonn E: Homocysteinelowering therapy and stroke risk, severity, and disability: additional findings from the HOPE 2 trial. Stroke 2009, 40:1365-1372.

48. Narshi CB, Giles IP, Rahman A: The endothelium: an interface between autoimmunity and atherosclerosis in systemic lupus erythematosus? Lupus 2011, 20:5-13.

49. do Prado R, D'Almeida VM, Guerra-Shinohara E, Galdieri LC, Terreri MT, Hilario $\mathrm{MO}$ : Increased concentration of plasma homocysteine in children with systemic lupus erythematosus. Clin Exp Rheumatol 2006, 24:594-598.

50. Lee PY, Li Y, Richards HB, Chan FS, Zhuang H, Narain S, Butfiloski EJ, Sobel ES, Reeves WH, Segal MS: Type I interferon as a novel risk factor for endothelial progenitor cell depletion and endothelial dysfunction in systemic lupus erythematosus. Arthritis Rheum 2007, 56:3759-3769.

51. Thacker SG, Berthier CC, Mattinzoli D, Rastaldi MP, Kretzler M, Kaplan MJ: The detrimental effects of IFN- $a$ on vasculogenesis in lupus are mediated by repression of IL-1 pathways: potential role in atherogenesis and renal vascular rarefaction. J Immunol 2010, 185:4457-4469.

52. Li J, Fu Q, Cui H, Qu B, Pan W, Shen N, Bao C: Interferon-alpha priming promotes lipid uptake and macrophage-derived foam cell formation a novel link between interferon-alpha and atherosclerosis in lupus. Arthritis Rheum 2011, 63:492-502.

53. Goossens P, Gijbels MJ, Zernecke A, Eijgelaar W, Vergouwe MN, van der Made I, Vanderlocht J, Beckers L, Buurman WA, Daemen MJ, Daemen MJ, Kalinke U, Weber C, Lutgens E, de Winther MP: Myeloid type I interferon signaling promotes atherosclerosis by stimulating macrophage recruitment to lesions. Cell Metab 2010, 12:142-153.

54. Lood C, Amisten S, Gullstrand B, Jonsen A, Allhorn M, Truedsson L, Sturfelt G, Erlinge D, Bengtsson AA: Platelet transcriptional profile and protein expression in patients with systemic lupus erythematosus: up-regulation of the type I interferon system is strongly associated with vascular disease. Blood 2010, 116:1951-1957.

55. Somers EC, Zhao W, Lewis EE, Wang L, Wing JJ, Sundaram B, Kazerooni EA, McCune WJ, Kaplan MJ: Type I interferons are associated with subclinical markers of cardiovascular disease in a cohort of systemic lupus erythematosus patients. PLoS One 2012, 7:e37000.

56. Bennett L, Palucka AK, Arce E, Cantrell V, Borvak J, Banchereau J, Pascual V: Interferon and granulopoiesis signatures in systemic lupus erythematosus blood. J Exp Med 2003, 197:711-723.

57. Danesh J, Kaptoge S, Mann AG, Sarwar N, Wood A, Angleman SB, Wensley F, Higgins JP, Lennon L, Eiriksdottir G, Rumley A, Whincup PH, Lowe GD, Gudnason V: Long-term interleukin-6 levels and subsequent risk of coronary heart disease: two new prospective studies and a systematic review. PLoS Med 2008, 5(4)::78.

58. Ridker PM, Rifai N, Stampfer MJ, Hennekens CH: Plasma concentration of interleukin- 6 and the risk of future myocardial infarction among apparently healthy men. Circulation 2000, 101:1767-1772.

59. Svenungsson E, Fei GZ, Jensen-Urstad K, de Faire U, Hamsten A, Frostegard J: TNF-alpha: a link between hypertriglyceridaemia and inflammation in SLE patients with cardiovascular disease. Lupus 2003, 12:454-461.

60. Asanuma Y, Chung CP, Oeser A, Shintani A, Stanley E, Raggi P, Stein CM: Increased concentration of proatherogenic inflammatory cytokines in systemic lupus erythematosus: relationship to cardiovascular risk factors. J Rheumatol 2006, 33:539-545.

61. Chung CP, Oeser A, Solus J, Avalos I, Gebretsadik T, Shintani A, Linton MF, Fazio S, Stein CM: Inflammatory mechanisms affecting the lipid profile in patients with systemic lupus erythematosus. J Rheumatol 2007, 34:1849-1854

62. Rua-Figueroa I, Arencibia-Mireles O, Elvira M, Erausquin C, Ojeda S, Francisco F, Naranjo A, Rodriguez-Gallego C, Garcia-Laorden I, Rodriguez-Perez J, Rodríguez-Lozano C: Factors involved in the progress of preclinical atherosclerosis associated with systemic lupus erythematosus: a 2-year longitudinal study. Ann Rheum Dis 2010, 69:1136-1139.

63. Sabio JM, Vargas-Hitos J, Zamora-Pasadas M, Mediavilla JD, Navarrete N, Ramirez A, Hidalgo-Tenorio C, Jaimez L, Martin J, Jimenez-Alonso J: Metabolic syndrome is associated with increased arterial stiffness and biomarkers of subclinical atherosclerosis in patients with systemic lupus erythematosus. J Rheumatol 2009, 36:2204-2211.

64. Roman MJ, Shanker BA, Davis A, Lockshin MD, Sammaritano L, Simantov R, Crow MK, Schwartz JE, Paget SA, Devereux RB, Salmon JE: Prevalence and correlates of accelerated atherosclerosis in systemic lupus erythematosus. NEngl J Med 2003, 349:2399-2406.

65. Pischon T, Girman CJ, Hotamisligil GS, Rifai N, Hu FB, Rimm EB: Plasma adiponectin levels and risk of myocardial infarction in men. JAMA 2004, 291:1730-1737.

66. Chung CP, Long AG, Solus JF, Rho YH, Oeser A, Raggi P, Stein CM: Adipocytokines in systemic lupus erythematosus: relationship to inflammation, insulin resistance and coronary atherosclerosis. Lupus 2009 18:799-806.

67. Reynolds HR, Buyon J, Kim M, Rivera TL, Izmirly P, Tunick P, Clancy RM: Association of plasma soluble E-selectin and adiponectin with carotid plaque in patients with systemic lupus erythematosus. Atherosclerosis 2010, 210:569-574.

68. McMahon M, Skaggs BJ, Sahakian L, Grossman J, Fitzgerald J, Ragavendra N, Charles-Schoeman C, Chernishof M, Gorn A, Witztum JL, Wong WK, Weisman M, Wallace DJ, La Cava A, Hahn BH: High plasma leptin levels confer increased risk of atherosclerosis in women with systemic lupus erythematosus, and are associated with inflammatory oxidised lipids. Ann Rheum Dis 2011, 70:1619-1624.

69. Baker JF, Morales M, Qatanani M, Cucchiara A, Nackos E, Lazar MA, Teff K, von 
Feldt JM: Resistin levels in lupus and associations with disease-specific measures, insulin resistance, and coronary calcification. J Rheumatol 2011 38:2369-2375

70. Al M, Ng L, Tyrrell P, Bargman J, Bradley T, Silverman E: Adipokines as novel biomarkers in paediatric systemic lupus erythematosus. Rheumatology (Oxford) 2009, 48:497-501.

71. Svenungsson E, Jensen-Urstad K, Heimburger M, Silveira A, Hamsten A, de Faire U, Witztum JL, Frostegard J: Risk factors for cardiovascular disease in systemic lupus erythematosus. Circulation 2001, 104:1887-1893.

72. Sule S, Fivush B, Neu A, Furth S: Increased risk of death in pediatric and adult patients with ESRD secondary to lupus. Pediatr Nephrol 2011, 26:93-98

73. Rinat C, Becker-Cohen R, Nir A, Feinstein S, Shemesh D, Algur N, Ben Shalom E, Farber B, Frishberg Y: A comprehensive study of cardiovascular risk factors, cardiac function and vascular disease in children with chronic renal failure. Nephrol Dial Transplant 2010, 25:785-793.

74. Litwin M, Wuhl E, Jourdan C, Niemirska A, Schenk JP, Jobs K, Grenda R, Wawer $\mathrm{ZT}$, Rajszys $\mathrm{P}$, Mehls O, Schaefer F: Evolution of large-vessel arteriopathy in paediatric patients with chronic kidney disease. Nephrol Dial Transplant 2008, 23:2552-2557.

75. Tucker PS, Dalbo VJ, Han T, Kingsley MI: Clinical and research markers of oxidative stress in chronic kidney disease. Biomarkers 2013, 18:103-115.

76. Luksha N, Luksha L, Carrero JJ, Hammarqvist F, Stenvinkel P, Kublickiene K: Impaired resistance artery function in patients with end-stage renal disease. Clin Sci 2011, 120:525-536.

77. Yilmaz MI, Stenvinkel P, Sonmez A, Saglam M, Yaman H, Kilic S, Eyileten T, Caglar K, Oguz Y, Vural A, Çakar M, Altun B, Yenicesu M, Carrero JJ: Vascular health, systemic inflammation and progressive reduction in kidney function; clinical determinants and impact on cardiovascular outcomes. Nephrol Dial Transplant 2011, 26:3537-3543

78. Moody WE, Edwards NC, Madhani M, Chue CD, Steeds RP, Ferro CJ, Townend $J \mathrm{~N}$ : Endothelial dysfunction and cardiovascular disease in early-stage chronic kidney disease: cause or association? Atherosclerosis 2012 223:86-94.

79. Muntner P, Hamm LL, Kusek JW, Chen J, Whelton PK, He J: The prevalence of nontraditional risk factors for coronary heart disease in patients with chronic kidney disease. Ann Internal Med 2004, 140:9-17.

80. Han C, Robinson DW Jr, Hackett MV, Paramore LC, Fraeman KH, Bala MV Cardiovascular disease and risk factors in patients with rheumatoid arthritis, psoriatic arthritis, and ankylosing spondylitis. J Rheumatol 2006, 33:2167-2172

81. Nurmohamed MT: Cardiovascular risk in rheumatoid arthritis. Autoimmun Rev 2009, 8:663-667.

82. Gorska A, Rutkowska-Sak L, Musiej-Nowakowska E, Chlabicz S, Gorski S: [Nailfold videocapillaroscopy - a useful tool for screening patients with juvenile idiopathic arthritis at the risk of development of premature atherosclerosis]. Postepy Hig Med Dosw (Online) 2010, 64:296-302.

83. Pietrewicz E, Urban M: [Early atherosclerosis changes in children with juvenile idiopathic arthritis]. Pol Merkur Lekarski 2007, 22:211-214.

84. Urban M, Pietrewicz E, Gorska A, Szczepanski W, Baran M: [Correlation between intima-media thickness in carotid artery and markers of epithelial cell dysfunction in patients with juvenile idiopathic arthritis] Med Wieku Rozwoj 2009, 13:277-282.

85. Argyropoulou MI, Kiortsis DN, Daskas N, Xydis V, Mavridis A, Efremidis SC, Siamopoulou A: Distensibility and pulse wave velocity of the thoracic aorta in patients with juvenile idiopathic arthritis: an MRI study. Clin Exp Rheumatol 2003, 21:794-797.

86. Breda L, Di Marzio D, Giannini C, Gaspari S, Nozzi M, Scarinci A, Chiarelli F, Mohn A: Relationship between inflammatory markers, oxidant-antioxidant status and intima-media thickness in prepubertal children with juvenile idiopathic arthritis. Clin Res Cardiol 2013, 102:63-71.

87. Vlahos AP, Theocharis $\mathrm{P}$, Bechlioulis A, Naka KK, Vakalis K, Papamichael ND, Alfantaki S, Gartzonika K, Mavridis A, Michalis LK, Siamopoulou A: Changes in vascular function and structure in juvenile idiopathic arthritis. Arthritis Care Res (Hoboken) 2011, 63:1736-1744

88. Honkanen VE, Pelkonen P, Konttinen YT, Mussalo-Rauhamaa H, Lehto J, Westermarck T: Serum cholesterol and vitamins $A$ and $E$ in juvenile chronic arthritis. Clin Exp Rheumatol 1990, 8:187-191.

89. Marangoni RG, Hayata AL, Borba EF, Azevedo PM, Bonfa E, Schainberg CG: Decreased high-density lipoprotein cholesterol levels in polyarticular juvenile idiopathic arthritis. Clinics (Sao Paulo) 2011, 66:1549-1552.
90. Musiej-Nowakowska E, Zawadzka F, Wesolowska H, Mikolajew M: Serum lipid concentrations in juvenile rheumatoid arthritis. Acta Univ Carol Med (Praha) 1991, 37:46-49

91. Tselepis AD, Elisaf M, Besis S, Karabina SA, Chapman MJ, Siamopoulou A: Association of the inflammatory state in active juvenile rheumatoid arthritis with hypo-high-density lipoproteinemia and reduced lipoprotein-associated platelet-activating factor acetylhydrolase activity. Arthritis Rheum 1999, 42:373-383.

92. Ilowite NT, Samuel P, Beseler L, Jacobson MS: Dyslipoproteinemia in juvenile rheumatoid arthritis. J Pediatr 1989, 114:823-826.

93. Bakkaloglu A, Kirel B, Ozen S, Saatci U, Topaloglu, Besbas N: Plasma lipids and lipoproteins in juvenile chronic arthritis. Clin Rheumatol 1996, 15:341-345.

94. De Benedetti F, Brunner HI, Ruperto N, Kenwright A, Wright S, Calvo I, Cuttica R, Ravelli A, Schneider R, Woo P, Wouters C, Xavier R, Zemel L, Baildam E, Burgos-Vargas R, Dolezalova P, Garay SM, Merino R, Joos R, Grom A, Wulffraat N, Zuber Z, Zulian F, Lovell D, Martini A; PRINTO; PRCSG: Randomized trial of tocilizumab in systemic juvenile idiopathic arthritis. N Engl J Med 2012 367:2385-2395.

95. Goncalves M, D'Almeida V, Guerra-Shinohara EM, Galdieri LC, Len CA, Hilario MO: Homocysteine and lipid profile in children with Juvenile Idiopathic Arthritis. Pediatr Rheumatol Online J 2007, 5:2.

96. Huemer M, Fodinger M, Huemer C, Sailer-Hock M, Falger J, Rettenbacher A, Bernecker M, Artacker G, Kenzian H, Lang T, Stöckler-Ipsiroglu S: Hyperhomocysteinemia in children with juvenile idiopathic arthritis is not influenced by methotrexate treatment and folic acid supplementation: a pilot study. Clin Exp Rheumatol 2003, 21:249-255.

97. Huemer M, Huemer C, Ulmer H, Crone J, Fodinger M, Falger J, Sailer-Hock M: No evidence for hyperhomocysteinemia or increased prevalence of genetic polymorphisms in the homocysteine pathway in patients with moderate juvenile idiopathic arthritis. J Rheumatol 2005, 32:170-174

98. Cantarini L, Simonini G, Fioravanti A, Generoso M, Bacarelli MR, Dini E, Galeazzi M, Cimaz R: Circulating levels of the adipokines vaspin and omentin in patients with juvenile idiopathic arthritis, and relation to disease activity. Clin Exp Rheumatol 2011, 29:1044-1048.

99. Tan BK, Adya R, Randeva HS: Omentin: a novel link between inflammation, diabesity, and cardiovascular disease. Trends Cardiovasc Med 2010, 20:143-148.

100. Yamawaki H, Kuramoto J, Kameshima S, Usui T, Okada M, Hara Y: Omentin, a novel adipocytokine inhibits TNF-induced vascular inflammation in human endothelial cells. Biochem Biophys Res Commun 2011, 408:339-343.

101. Elwakkad AS, Said RN, Muhammad SI, Saleh MT, Elhamshary A: Role for leptin and prolactin in human juvenile rheumatic diseases. Pak J Biol Sci 2007, 10:1984-1989.

102. Perfetto F, Tarquini R, Simonini G, Bindi G, Mancuso F, Guiducci S, MatucciCerinic M, Falcini F: Circulating leptin levels in juvenile idiopathic arthritis: a marker of nutritional status? Ann Rheum Dis 2005, 64:149-152.

103. Caetano MC, Sarni RO, Terreri MT, Ortiz TT, Pinheiro M, de Souza FI, Hilario MO: Excess of adiposity in female children and adolescents with juvenile idiopathic arthritis. Clin Rheumatol 2012, 31:967-971.

104. Tisseverasinghe A, Bernatsky S, Pineau CA: Arterial events in persons with dermatomyositis and polymyositis. J Rheumatol 2009, 36:1943-1946.

105. Zoller B, Li X, Sundquist J, Sundquist K: Risk of subsequent coronary heart disease in patients hospitalized for immune-mediated diseases: a nationwide follow-up study from Sweden. PLoS One 2012, 7:e33442.

106. Eimer MJ, Brickman WJ, Seshadri R, Ramsey-Goldman R, McPherson DD, Smulevitz B, Stone NJ, Pachman LM: Clinical status and cardiovascular risk profile of adults with a history of juvenile dermatomyositis. J Pediatr 2011 , 159:795-801.

107. Bingham A, Mamyrova G, Rother Kl, Oral E, Cochran E, Premkumar A, Kleiner D, James-Newton L, Targoff IN, Pandey JP, Carrick DM, Sebring N, O'Hanlon TP, Ruiz-Hidalgo M, Turner M, Gordon LB, Laborda J, Bauer SR, Blackshear PJ, Imundo L, Miller FW, Rider LG; Childhood Myositis Heterogeneity Study Group: Predictors of acquired lipodystrophy in juvenile-onset dermatomyositis and a gradient of severity. Medicine (Baltimore) 2008, 87:70-86.

108. McCann LJ, Juggins AD, Maillard SM, Wedderburn LR, Davidson JE, Murray KJ, Pilkington CA: The Juvenile Dermatomyositis National Registry and Repository (UK and Ireland) - clinical characteristics of children recruited within the first 5 yr. Rheumatology (Oxford) 2006, 45:1255-1260.

109. Verma S, Singh S, Bhalla AK, Khullar M: Study of subcutaneous fat in children with juvenile dermatomyositis. Arthritis Rheum 2006, 55:564-568. 
110. Coyle K, Rother KI, Weise M, Ahmed A, Miller FW, Rider LG: Metabolic abnormalities and cardiovascular risk factors in children with myositis. $J$ Pediatr 2009, 155:882-887.

111. Baechler EC, Bilgic H, Reed AM: Type I interferon pathway in adult and juvenile dermatomyositis. Arthritis Res Ther 2011, 13:249.

112. Li S, Chen W, Srinivasan SR, Bond MG, Tang R, Urbina EM, Berenson GS: Childhood cardiovascular risk factors and carotid vascular changes in adulthood: the Bogalusa Heart Study. JAMA 2003, 290:2271-2276.

113. Raitakari OT, Juonala M, Kahonen M, Taittonen L, Laitinen T, Maki-Torkko N, Jarvisalo MJ, Uhari M, Jokinen E, Ronnemaa T, Akerblom HK, Viikari JS: Cardiovascular risk factors in childhood and carotid artery intima-media thickness in adulthood: the Cardiovascular Risk in Young Finns Study. JAMA 2003, 290:2277-2283

114. Kavey RE, Allada V, Daniels SR, Hayman LL, McCrindle BW, Newburger JW, Parekh RS, Steinberger J: Cardiovascular risk reduction in high-risk pediatric patients: a scientific statement from the American Heart Association Expert Panel on Population and Prevention Science; the Councils on Cardiovascular Disease in the Young, Epidemiology and Prevention, Nutrition, Physical Activity and Metabolism, High Blood Pressure Research, Cardiovascular Nursing, and the Kidney in Heart Disease; and the Interdisciplinary Working Group on Quality of Care and Outcomes Research: endorsed by the American Academy of Pediatrics. Circulation 2006, 114:2710-2738.

115. Hodis HN, Quismorio FP, Jr, Wickham E, Blankenhorn DH: The lipid, lipoprotein, and apolipoprotein effects of hydroxychloroquine in patients with systemic lupus erythematosus. J Rheumatol 1993, 20:661-665.

116. Petri M, Lakatta C, Magder L, Goldman D: Effect of prednisone and hydroxychloroquine on coronary artery disease risk factors in systemic lupus erythematosus: a longitudinal data analysis. Am J Med 1994, 96:254-259.

117. Tam LS, Gladman DD, Hallett DC, Rahman P, Urowitz MB: Effect of antimalarial agents on the fasting lipid profile in systemic lupus erythematosus. J Rheumatol 2000, 27:2142-2145.

118. Penn SK, Kao AH, Schott LL, Elliott JR, Toledo FG, Kuller L, Manzi S, Wasko MC: Hydroxychloroquine and glycemia in women with rheumatoid arthritis and systemic lupus erythematosus. J Rheumatol 2010, 37:1136-1142.

119. Westlake SL, Colebatch AN, Baird J, Curzen N, Kiely P, Quinn M, Choy E, Ostor AJK, Edwards CJ: Tumour necrosis factor antagonists and the risk of cardiovascular disease in patients with rheumatoid arthritis: a systematic literature review. Rheumatology 2011, 50:518-531.

120. Major AS, Fazio S, Linton MF: B-lymphocyte deficiency increases atherosclerosis in LDL receptor-null mice. Arterioscler Thromb Vasc Biol 2002, 22:1892-1898
121. Ait-Oufella H, Herbin O, Bouaziz JD, Binder CJ, Uyttenhove C, Laurans L, Taleb S, Van Vre E, Esposito B, Vilar J, Sirvent J, Van Snick J, Tedgui A, Tedder TF, Mallat $Z: B$ cell depletion reduces the development of atherosclerosis in mice. J Exp Med 2010, 207:1579-1587.

122. Bulgarelli A, Martins Dias AA, Caramelli B, Maranhao RC: Treatment with methotrexate inhibits atherogenesis in cholesterol-fed rabbits. J Cardiovasc Pharmacol 2012, 59:308-314.

123. Toloza SM, Uribe AG, McGwin G, Jr, Alarcon GS, Fessler BJ, Bastian HM, Vila LM Wu R, Shoenfeld Y, Roseman JM, Reveille JD; LUMINA Study Group: Systemic lupus erythematosus in a multiethnic US cohort (LUMINA). XXIII. Baseline predictors of vascular events. Arthritis Rheum 2004, 50:3947-3957.

124. van Leuven SI, Mendez-Fernandez YV, Wilhelm AJ, Wade NS, Gabriel CL, Kastelein JJ, Stroes ES, Tak PP, Major AS: Mycophenolate mofetil but not atorvastatin attenuates atherosclerosis in lupus-prone $\mathrm{LDLr}^{-/-}$mice. Ann Rheum Dis 2012, 71:408-414.

125. van Leuven SI, van Wijk DF, Volger OL, de Vries JP, van der Loos CM, de Kleijn DV, Horrevoets AJ, Tak PP, van der Wal AC, de Boer OJ, Pasterkamp G, Hayden MR, Kastelein JJ, Stroes ES: Mycophenolate mofetil attenuates plaque inflammation in patients with symptomatic carotid artery stenosis. Atherosclerosis 2010, 211:231-236.

126. Watson L, Leone V, Pilkington C, Tullus K, Rangaraj S, McDonagh JE, GardnerMedwin J, Wilkinson N, Riley P, Tizard J, Armon K, Sinha MD, loannou Y, Archer N, Bailey K, Davidson J, Baildam EM, Cleary G, McCann LJ, Beresford MW; UK Juvenile-Onset Systemic Lupus Erythematosus Study Group: Disease activity, severity, and damage in the UK Juvenile-Onset Systemic Lupus Erythematosus Cohort. Arthritis Rheum 2012, 64:2356-2365.

127. Hasija R, Pistorio A, Ravelli A, Demirkaya E, Khubchandani R, Guseinova D, Malattia C, Canhao H, Harel L, Foell D, Wouters C, De Cunto C, Huemer C, Kimura Y, Mangge H, Minetti C, Nordal EB, Philippet P, Garozzo R, Martini A, Ruperto N; Pediatric Rheumatology International Trials Organization: Therapeutic approaches in the treatment of juvenile dermatomyositis in patients with recent-onset disease and in those experiencing disease flare: an international multicenter PRINTO study. Arthritis Rheum 2011, 63:3142-3152.

doi:10.1186/ar4212

Cite this article as: Barsalou J, et al: Cardiovascular risk in pediatric-onset rheumatological diseases. Arthritis Research \& Therapy 2013, 15:212. 